\title{
A NOTE ON THE MUSIC
}

Wherever you see a $G$ clef included in the text (as shown below), you will find a link to a piece of music that was composed by Lear or was sung by him. There are twelve specially recorded pieces in this audio trail. Readers are invited to listen along. The music is at edwardlearsmusic.com.
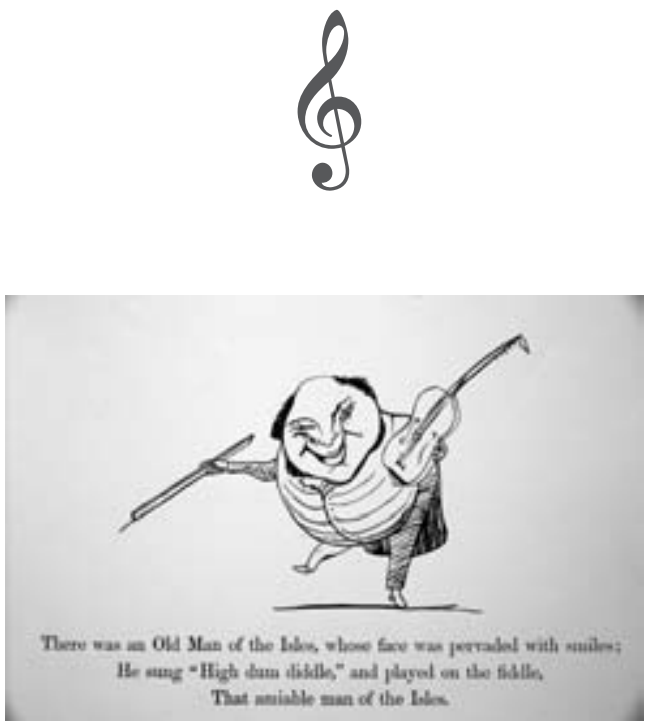

Inventing Edward Lear 
